\title{
Stimulus context and absolute magnitude estimation: A study of individual differences
}

\author{
GEORGE A. GESCHEIDER \\ Hamilton College, Clinton, New York \\ and Institute for Sensory Research, Syracuse, New York \\ and \\ BARBARA A. HUGHSON \\ Hamilton College, Clinton, New York
}

\begin{abstract}
The effect of stimulus context on absolute-magnitude-estimation (AME) judgments was examined by determining whether the loudness judgment of a tone is influenced by the intensities of other tones presented within the session. A group of 18 subjects was tested in separate sessions in which they judged stimuli within either a low (10-60 dBSL) or a high (40-90 dBSL) range of intensities. Examination of the results of individual subjects revealed that judgments of stimuli common to the two ranges were, in most subjects, unaffected or only slightly affected by the position of the range. The judgments of 2 subjects who failed to follow the instructions, however, showed very large context effects due to changing the stimulus range. The results of a second experiment, in which 22 subjects judged the loudness of tones within either a narrow (35-65 dBSL) or a wide (20-80 dBSL) range, revealed that, in all but 1 subject, the width of the range had no systematic effect on the loudness judgments of stimuli common to both ranges. This was also true 1 month later when 16 of the subjects returned to the laboratory to judge the loudness of tones within an even wider range of 10-90 dBSL. It was concluded that AME judgments are relatively insensitive to the potential biasing influences of stimulus context.
\end{abstract}

An important question recently asked is whether or not there is anything absolute about absolute magnitude estimation (Gescheider \& Bolanowski, 1991). The answer is the outcome of a long history of research (Hellman \& Zwislocki, 1961, 1963; Zwislocki, 1978, 1983b; Zwislocki \& Goodman, 1980) and is rooted in the problem of controlling bias in magnitude-estimation experiments. Absolute magnitude estimation (AME) requires subjects to match their subjective impression of the size of a number to their impression of the intensity of a stimulus and to do so independently of prior matches. The method is based on the hypothesis that, at a particular time and in a particular setting, a subject has a strong tendency to assign a number to a stimulus in such a way that their psychological magnitudes match. Forcing the subject to use an arbitrary modulus associated with a particular standard stimulus can violate this tendency to match psychological magnitudes, thus resulting in bias. According to the AME hypothesis, subjects are capable of making unbiased numerical judgments of psychological magnitude only when they are permitted to use their own natural units.

The evidence that a subject judges psychological magnitude on an absolute rather than on a ratio scale comes

This research was supported in part by Grants R0 1 DC-00098 and P0 1 DC-00380 from the National Institutes of Health, U.S. Department of Health and Human Services. We would like to thank Ronald Verrillo and Jozef Zwislocki for their helpful comments. Correspondence should be addressed to George A. Gescheider, Department of Psychology, Hamilton College, Clinton, NY 13323. from findings on the effects of the values of the standard stimulus and the modulus in magnitude estimation. In accordance with the definition of ratio scales (Stevens, 1951), a subject's numerical judgments of psychological magnitudes should be invariant to within a multiplicative transformation when the value of the modulus and/or standard stimulus is changed. Thus, it should be possible to make valid judgments of all stimuli in proportion to an arbitrary modulus if the subject is capable of assigning numbers in proportion to the ratios of their sensations. The work of Stevens (1956) and Hellman and Zwislocki (1961) on loudness scaling, in which the effects of using a standard stimulus with a particular modulus as a reference were investigated, casts doubt on the ratio-scaling hypothesis. In these studies, it was found that the value of the modulus had a substantial effect on the form of the loudness function. Specifically, the scale values obtained with one modulus were not linearly related by a multiplicative constant to those obtained with a different modulus. Hellman and Zwislocki interpreted these findings as evidence that subjects tend to make judgments of psychological magnitude on an absolute scale with a fixed unit rather than on a ratio scale with an arbitrary unit. According to this hypothesis, subjects tend to assign a number to a stimulus in such a way that their psychological impression of the size of the number matches their impression of the psychological magnitude of the stimulus and, consequently, forcing them to do otherwise, with a standard stimulus having a defined modulus, causes bias. 
The nature of the bias is that although magnitude estimations of stimuli near the standard are judged relative to that standard, stimuli distant from the standard are not. Instead, they appear to be judged on the subject's own natural (i.e., absolute) scale (Hellman \& Zwislocki, 1961). The end result is that the form of the psychologicalmagnitude function is not independent of the values of the standard stimulus and is therefore biased.

Also relevant is the question of whether the resulting psychophysical scale has the properties of an absolute scale in the sense of the meaning of the term "absolute" in measurement theory. According to Stevens (1951), nominal, ordinal, interval, and ratio scales form a hierarchy with respect to the degree of isomorphism that exists between the scale and properties of the number system. Each type of scale contains characteristics of its own, as well as those of the types below it. For example, the highest type of scale, the ratio scale, in addition to having a natural origin, also has the property of equal intervals contained in the interval scale, order contained in the ordinal scale, and identity contained in the nominal scale. According to Stevens's classification system, an absolute scale would consist of a ratio scale with a fixed unit and would contain all the properties of the other scale types (see Gescheider \& Bolanowski, 1991). At the present time, the question of whether a psychophysical scale meets the requirements of this special form of ratio scale must be answered empirically through tests of additivity and transitivity.

Additivity and transitivity have been demonstrated for AME data. Using the conjoint measurement method (Luce \& Tukey, 1964), Zwislocki (1983b) demonstrated additivity of loudness estimations for tones having frequencies in widely different critical bands. Also suggestive of additivity are the findings of linear binaural loudness summation (Hellman \& Zwislocki, 1963) and linear binocular brightness summation of a ganzfeld (Bolanowski, 1987). Transitivity has been demonstrated in studies in which subjects made cross-modality matches (Bolanowski, Zwislocki, \& Gescheider, 1991; Collins \& Gescheider, 1989 ), as well as those in which subjects made intramodality matches of the loudness of tones of different frequencies (Hellman, 1976), the loudness of tones presented in the presence and in the absence of masking noise (Hellman \& Zwislocki, 1964), and the subjective magnitude of vibrotactile stimuli of different frequencies (Verrillo, Fraioli, \& Smith, 1969). The general finding is that stimuli that have been assigned the same number in AME will be judged to have the same sensation magnitude in a matching task.

Do absolute magnitude estimations depend on stimulus context? There has been some misunderstanding concerning the implications of stimulus-context effects for the absolute-magnitude-estimation hypothesis. Although some researchers interpret stimulus-context effects, in which absolute magnitude estimations of a stimulus depend either on the values of other stimuli presented in the session (e.g., Mellers, 1983) or on the values of stimuli presented in an earlier session (Foley, Cross, \& O'Reilly, 1990), as evi- dence against the hypothesis, it has been correctly pointed out by one of its two originators (Zwislocki, 1983a) that the hypothesis is still valid (also see Gescheider, 1988, for a review). According to Zwislocki, a scale is called "absolute" not because it cannot be biased, but because it has the formal mathematical property of having a fixed unit.

Nevertheless, if AME is to be useful as an experimental technique for measuring psychological magnitude, it is important to assess the degree to which the results of the method are biased by stimulus context. Thus far, the results are ambiguous with regard to the magnitude of context effects for AME. In the judgment of loudness, Zwislocki and Goodman (1980) found the subjects' responses to be fairly free from stimulus-context effects. Ward (1987) reported context effects for several scaling methods, including AME, but they were smaller for AME and ratio magnitude estimation than they were for category rating. Mellers (1983), however, found substantial context effects for absolute magnitude estimation. In all of these studies, context effects were evaluated by determining whether or not the average response of a group of subjects to a particular stimulus was influenced by the distribution of other stimulus values presented in the experimental situation. In the present study on the AME of loudness, this same procedure was used to test for context effects, but, in addition, the responses of individual subjects were examined. We felt that a study of individual differences in susceptibility to context effects could help us gain an understanding of their origin and, in so doing, provide some insights on how to control this potential source of bias in the scaling experiment.

\section{EXPERIMENT 1}

The purpose of this experiment was to investigate the effects of the position of the stimulus range on the AME of loudness. The question is whether or not a stimulus will be assigned the same number in AME when it is presented in the context of low-intensity stimuli as when it is presented in the context of high-intensity stimuli. The group data of Zwislocki and Goodman (1980) showed AME judgments to be little affected by the context of the stimulus range. In this experiment, we examined the effects of context on both group and individual subject data.

\section{Method}

Subjects were 18 adults with normal hearing and no previous experience as subjects in psychophysical scaling experiments. ${ }^{1}$ On entering the laboratory, they were given the following absolutemagnitude-estimation instructions for the judgment of the subjective lengths of lines:

\footnotetext{
You have impressions of what is a long-, short-, and medium-length line. You also have impressions of what is a large-, small-, and mediumsize number. When I present a line on the screen, I would like you to assign a number to it so that your impression of the size of the number matches your impression of the length of the line. Do not try to measure the line or compare its length with those of other lines. Just try to look at each line and say a number that seems right for it. You can use any positive number that you want to. You can use decimals or fractions if you feel they are appropriate.
} 
The judgment of subjective line length was used as a simple training task (Stevens, 1975) to prepare subjects for judging the loudness of tones. The horizontal line was projected on a $180-\mathrm{cm}$-wide screen and was either $1,2,4,10,20,40$, or $100 \mathrm{~cm}$ in length and approximately $.5 \mathrm{~cm}$ in width. The distance between the subject and the screen was approximately $3.0 \mathrm{~m}$. Each line was presented three times in a random order.

After completion of the AME of subjective line length, instructions were given for the judgment of loudness. These instructions were essentially the same as those for subjective line length, but in this case, the subjects were told to match their impressions of the loudness of tones of varying sensation level with their impressions of the size of numbers. To prevent the possibility that the process of measuring auditory thresholds could later influence magnitude estimations, sensation level, expressed as decibels above threshold, was established by measuring the thresholds for 2 listeners with normal hearing who did not participate in the experiment. All sensation levels used in the experiment were referenced to the average of these thresholds. The loudness judgments were conducted in two separate sessions 1 day apart. One group of 9 subjects was presented on the 1st day with a low range of sensation levels (10, $20,30,40,50$, and $60 \mathrm{dBSL}$ ) and on the 2 nd day with a high range $(40,50,60,70,80$, and $90 \mathrm{dBSL})$. Another group of 9 subjects was first presented with the high range of intensities and on the 2nd day with the low range. The two ranges overlapped by $20 \mathrm{~dB}$, with the 40-, 50-, and 60-dBSL stimuli common to both ranges. The magnitude estimations of these values should not significantly change over the two sessions if judgments are free of the effects of stimulus context. During a session, tones of the six intensities were presented three times in a random order. The frequency of the tone generated by a Hewlett-Packard Model 200AB oscillator was $1000 \mathrm{~Hz}$; its intensity was controlled by a Hewlett-Packard Model 350D decade attenuator set after amplification by a General Radio Model 1206B unit amplifier. A Grason-Stadler Model 829 electronic switch was used to present the tone with a 10 -msec rise-decay time for $1,250 \mathrm{msec}$ every $2,500 \mathrm{msec}$ until the subject made a judgment of its loudness. Stimuli were presented through a loudspeaker located approximately $1.5 \mathrm{~m}$ in front of the subject. At the end of the second session, the subjects were required to describe the ways in which they made their decisions about assigning numbers to the loudness of tones. This information was valuable in determining whether or not the subjects had followed the instructions.

\section{Results and Discussion}

The data were examined as average loudness functions of groups of subjects, as well as loudness functions of individual subjects. Since group data were presented as geometric means, a widely accepted procedure used in magnitude-estimation experiments, the log values of individual subjects were used in all statistical analyses.

Group data. The geometric means of the group data are seen in Figure 1. Each data point is based on the average of the second and third judgments of a stimulus presented within a session and is the geometric mean of the results of 8 subjects. The form of the function is the typical power function for magnitude estimation of loudness, with an exponent of .31 between 40 and $90 \mathrm{dBSL}$ and an exponent approaching a value of 1.0 at intensities near threshold (e.g., Hellman \& Zwislocki, 1963, 1968; Rowley \& Studebaker, 1969; Zwislocki \& Goodman, 1980). The data of 2 subjects were omitted from this analysis, because, at the end of the experiment, these subjects reported their having used category scales rather than following

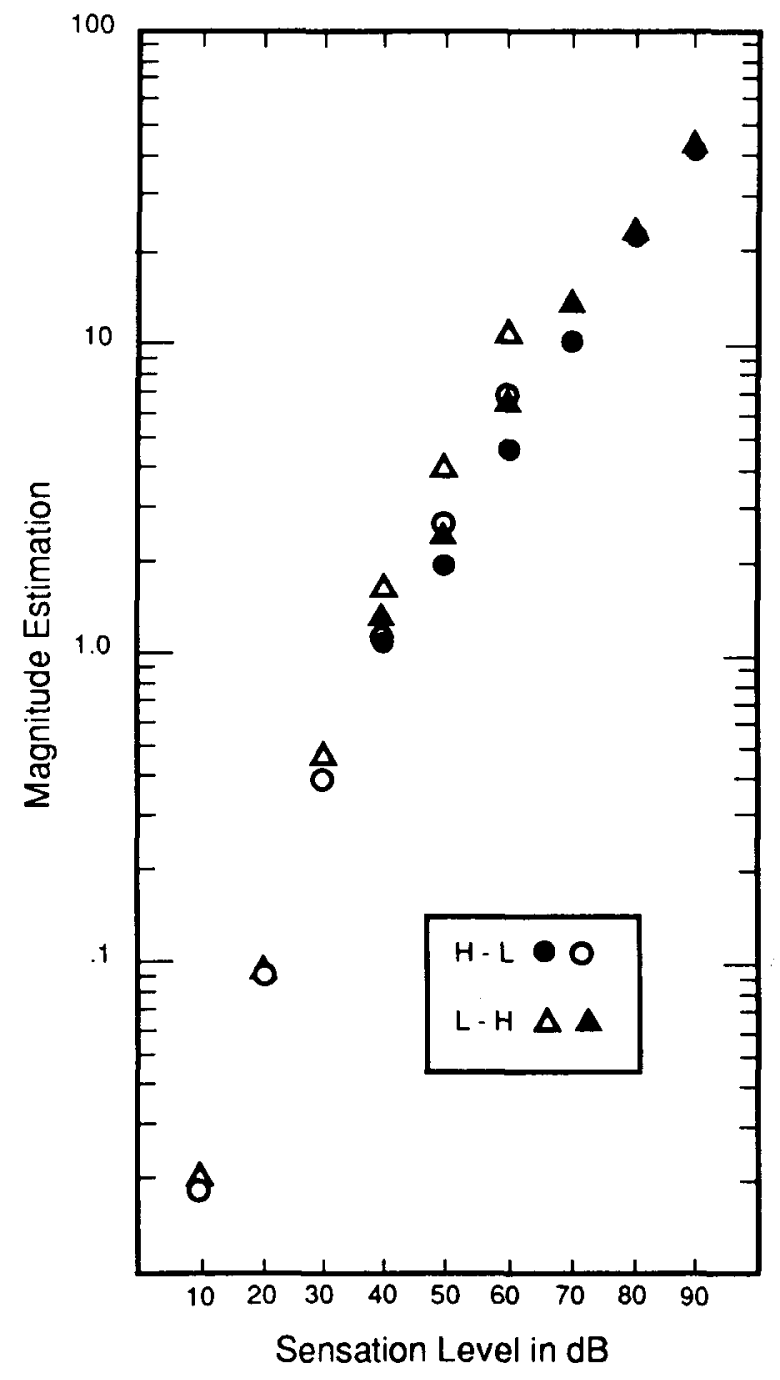

Figure 1. Geometric means of AME judgments as a function of the sensation level of the tone in decibels.

instructions and matching their subjective impressions of number size to loudness. The data of these subjects are presented in our consideration of the loudness functions of individual subjects.

Comparison of the data of the two groups of subjects, each group defined by the order of sessions within which they were presented with either the low or high range of sensation levels, revealed no significant differences in either the low range $[F(1,14)=.215, p>.05]$ or the high range $[F(1,14)=.125, p>.05]$. The sensation level $\times$ group interactions also fail to attain statistical significance either for the low range of sensation levels $[F(5,70)=.316, p>.05]$ or for the high range of sensation levels $[F(5,70)=.672, p>.05]$. It is clear from Figure 1 and from the results of the statistical analysis that the average data for the two groups are essentially identical. Thus, there is no evidence that judgments of stimuli within a range of sensation levels are influenced 
by previously made judgments of stimuli within a different range. For example, the two functions for the low range are the same, even though the one for the $\mathrm{L}-\mathrm{H}$ group was obtained in the first session, whereas the function for the H-L group was obtained in the second session after judging stimuli in the high range of sensation levels during the first session. The same independence of judgments from prior experience is seen in the data in the high sensation-level range. In this case, the functions of the two groups are the same in spite of the fact that the function was obtained first for the $\mathrm{H}-\mathrm{L}$ group and second, after a session of judging stimuli in the low range, for the $\mathrm{L}-\mathrm{H}$ group. The analysis favors the interpretation that AME data tend to be immune to the potential biasing effects of prior experience with a different set of stimulus values. Our results contrast sharply with those of Foley et al. (1990), who found AME judgments of the apparent size of triangles to be influenced by prior experience in judging a set of triangles that were in a different size range. These investigators interpreted this finding as evidence that AME judgments are not absolute. Another possible interpretation, however, is that the judgments were absolute, in that subjects correctly matched impressions of number size to impressions of triangle size, whereas their perceptions and/or conceptions of size were relative in that they were influenced by prior experience. Thus, although perception and cognition of sensory mag- nitudes are probably usually relative, the final assigning of numbers in AME may be absolute.

If a subject's match of subjective number size to the loudness of a sound is independent of the location of the range of sensation levels, then a single loudness function should be formed by combining the data from the low and high ranges of the two groups. The data of the first and second sessions contained in Figure 1 are replotted in Figure 2. Despite the displacement of the two subsets of data points obtained in Session 1, the conclusion that a single loudness function underlies the results from the two stimulus ranges is justified by the finding that the results obtained for the two groups in the overlapping sections of the two ranges $(40,50$, and $60 \mathrm{dBSL})$ were not statistically significant, as indicated by the insignificant main effect of groups $[F(1,14)=1.716, p>.05]$ and insignificant groups $\times$ sensation level interaction $[F(2,28)=$ $2.51, p>.05]$. Had the subjects' judgments been totally relative, both groups of subjects would have used similar response ranges even though the positions of the stimulus ranges were very different. In the most extreme models of relativity judgments, meaningless sensation-magnitude functions are produced because subjects have fixed response ranges that are fully applied to any stimulus range, no matter what its size or position. According to this view, the bottom of the response range is applied to the weakest stimulus, the top of the range is applied to the strongest,

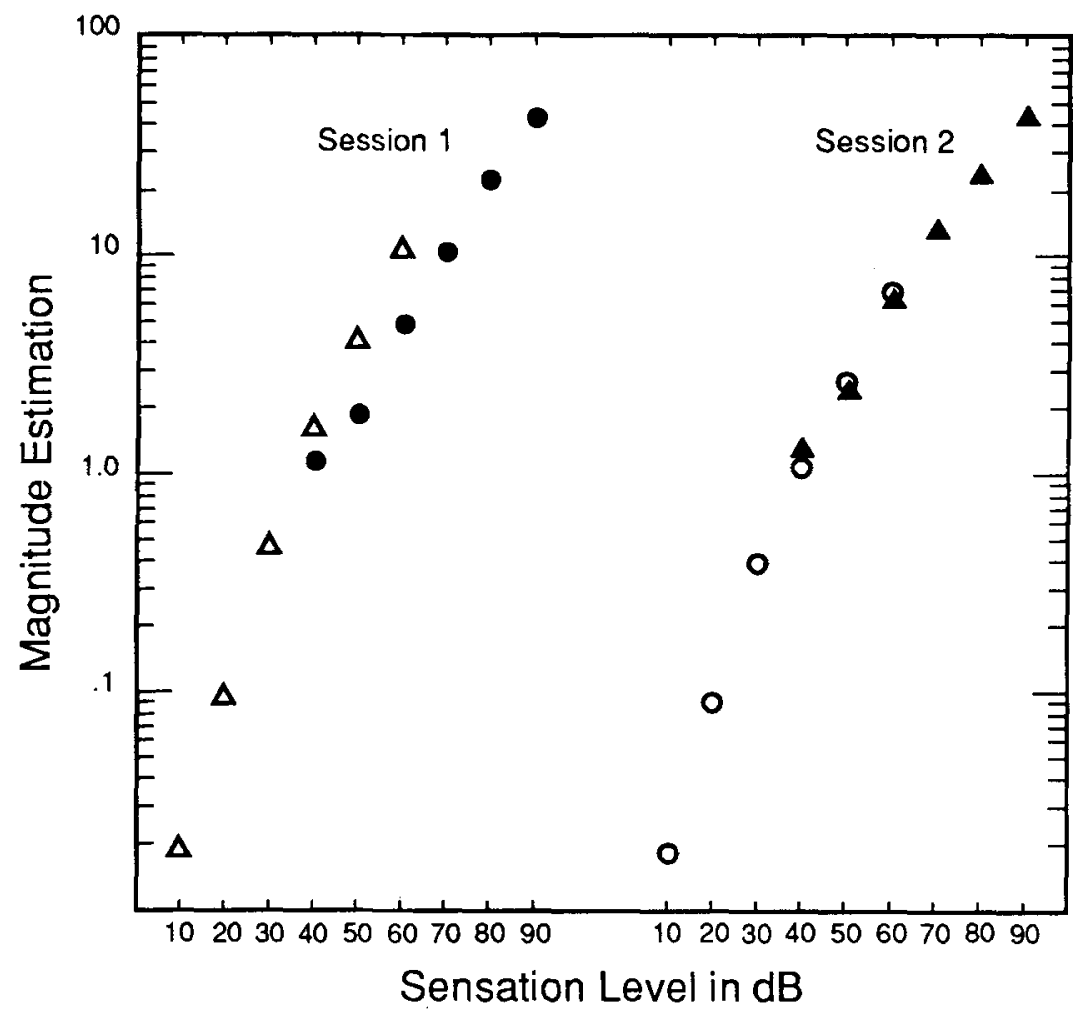

Figure 2. Geometric means of AME judgments as a function of the sensation level of the tone in decibels. Within each session, the low and high range data were obtained by different groups of 8 subjects. 
and stimuli between the extremes are judged relative to one another. If such relative judgments had occurred in our experiment, two separate loudness functions would have been obtained in which subjects had judged the subjective magnitudes of stimuli relative to others experienced in the session. The two loudness functions would be separated by $30 \mathrm{~dB}$ on the intensity axis with, in one case, subjects' assigning their lowest numbers to the 10-dBSL stimulus and their highest to the 60-dBSL stimulus and with, in the other case, subjects' assigning their lowest number to the 40-dBSL stimulus and their highest to the 90-dBSL stimulus. It is obvious that this did not happen, and, in fact, the absolute values of the numbers produced by the two independent groups of subjects seem to be determined by the absolute stimulus values rather than solely by the relative position of the stimuli within the stimulus range. It is noteworthy that this tendency of subjects to make context-independent rather than relative judgments is independent of prior experience with AME of loudness, as indicated by the fact that the data of the first session of the experiment represent the first time that any of the subjects had performed the task.

The results obtained from the two groups of subjects during the second session and shown in Figure 2 also demonstrate the context-independent nature of the subjects' judgments. Again, the results of the two groups, when plotted on the same graph, form a single loudness function. Results obtained for the overlapping sections of the two ranges did not differ significantly, as indicated by the insignificant main effect of groups $[F(1,14)=$ $.005, p>.05]$ and insignificant groups $\times$ sensation level interaction $[F(2,28)=.547, p>.05]$.

If stimulus context has no effect on AME judgments, then AME values of the same subjects obtained for the stimuli at 40,50 , and $60 \mathrm{dBSL}$ should be the same when they are presented within the context of a low range of stimuli (10-60 dBSL) as when they are presented within the context of a high range of stimuli (40-90 dBSL). The results plotted in Figure 3 show that this was approximately, but not entirely, true. It is clear that the overall forms of the loudness functions are well defined by combining the results obtained with the two overlapping stimulus ranges presented in the two sessions. It can also be seen, however, that the stimuli at 40,50 , and $60 \mathrm{dBSL}$ were judged to be louder when they were presented in the context of weaker stimuli than when they were judged in the context of stronger stimuli. This stimulus-context effect was statistically significant. An analysis of variance of the data for the stimuli at 40,50, and $60 \mathrm{dBSL}$ revealed that the main effect of stimulus range was significant $[F(1,4)=9.96, p<.01]$. That the magnitude of this context effect is dependent on sensation level, as indicated

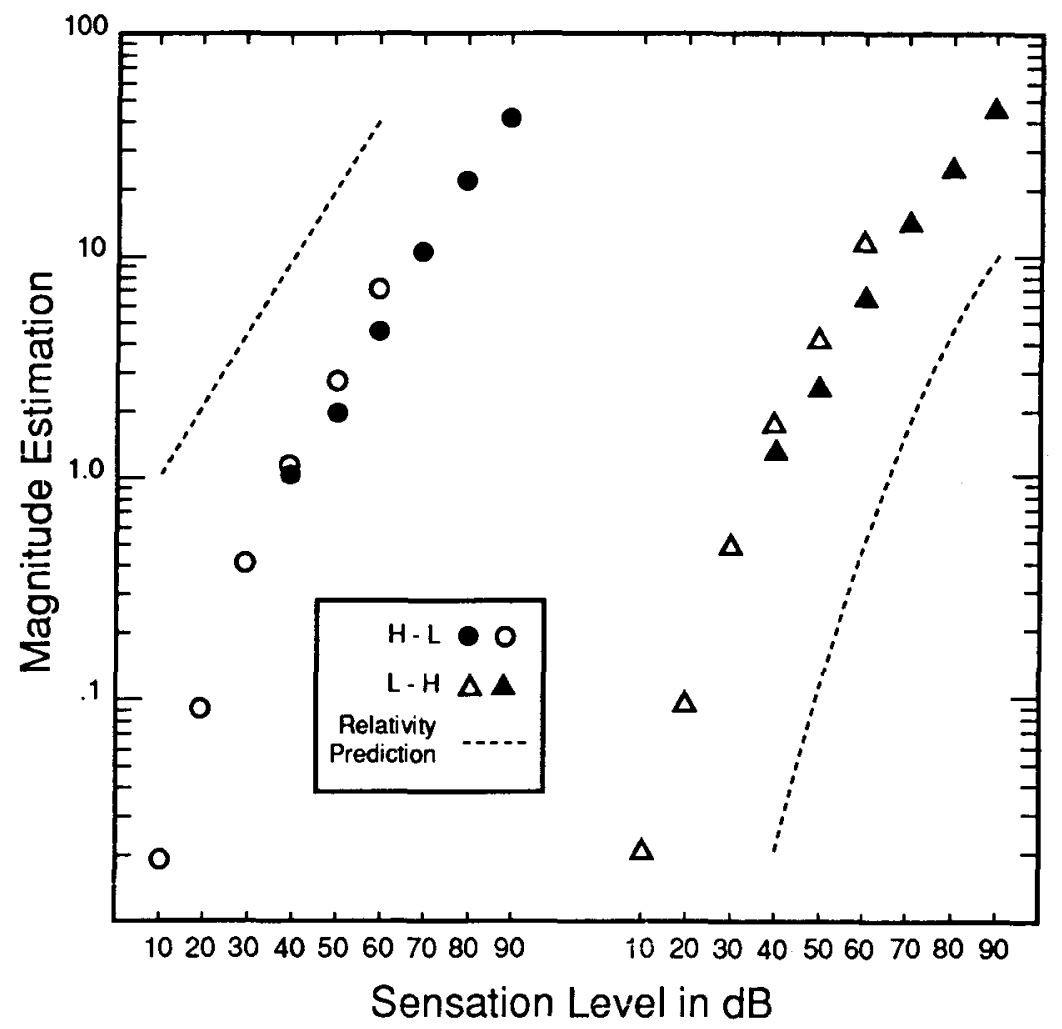

Figure 3. Geometric means of AME judgments as a function of the sensation level of the tone in decibels. Each function was determined for two separate groups of 8 subjects, one which was first tested with the high range and then the low range, the other which was first tested with the low range and then the high range. 
by the increasing difference in the functions as sensation level increases, is supported by the significant interaction of range with sensation level $[F(2,28)=5.03, p<.05]$. The range effect was found not to interact with the order of presentation of the ranges $[F(1,14)=.298, p>.05]$.

Reexamination of the Session 1 data of Figure 2 also reveals this tendency for subjects to judge stimuli as louder when they are presented with weaker, rather than with louder, stimuli. Perhaps the between-groups difference failed to attain statistical significance because of intersubject variability within the two groups, or perhaps the context effect only occurs when subjects are shifted from one stimulus range to another. It is pertinent to this issue that examination of the between groups comparison of Figure 8 in Zwislocki and Goodman (1980) also shows a slight tendency for stimuli to be judged as louder in the presence of weak, rather than strong, stimuli. However, examination of their Figure 9 indicates little, if any, tendency for context to influence judgments when the same subjects experienced a shift to a new position of the stimulus range in the second session.

One possible interpretation of the stimulus-range effect is that the range biased the subjects' responses; another interpretation is that the range did not bias responses but instead influenced the perceived magnitudes of the stimuli. Because the present experiment cannot determine which of these two explanations is correct, it seems appropriate to consider them both. According to the first explanation, subjects have a tendency to apply fixed response ranges to whatever stimulus range is presented. This concept is illustrated in Figure 3 by the dashed functions. For example, if this tendency were fully realized, the function of the $\mathrm{H}$-L group obtained for the low range on the 2 nd day would start at 1.0 and end at 42.0 , as did the function for the high range obtained on the 1st day. Since the range of stimuli on the first day was 40-90 dBSL and the range on the second day was 10-60 dBSL, the two functions should be separated on the sensation-level axis by $30 \mathrm{~dB}$. It is obvious that if there is a tendency to make such relative judgments in AME, it exists in a highly attenuated form compared with what it would be if judgments were entirely relative. The functions at $40-60 \mathrm{dBSL}$ for the two ranges were not separated by $30 \mathrm{~dB}$, as predicted by relative-judgment theory, but instead were separated by only 4-6 dB. This was also true for the L-H group, in which the function predicted for the 2 nd day from relativejudgment theory (seen as a dashed function) would start at 0.19 at $40 \mathrm{dBSL}$ and end at 11 at $90 \mathrm{dBSL}$. Again, the function for the 2 nd day for the points at 40,50 , and $60 \mathrm{dBSL}$ shifted by 4-6 dB in the direction of the 30-dB shift predicted from the relative-judgment hypothesis.

The alternative explanation of the context effects seen in this study is that the stimulus range experienced within a session can influence the perceived loudness of a stimulus. According to this hypothesis, the context effects seen in our study occur because moderately intense tones are perceived as louder when they are heard in the context of tones of lower intensity than when they are heard in the context of tones of higher intensity. It is well established that perceptual-contrast effects occur in all sensory modalities, and our results may be simply another example of the phenomenon. Results relevant to this hypothesis have been obtained by Ward (1982, 1985, 1986, 1990), who has argued that sequential dependencies in magnitude estimation in which the subject's response contrasts with the value of the previous stimulus are based on sensory processes. In loudness judgments, for example, a tone is judged to be louder if it is heard after the presentation of a weaker tone than after the presentation of a stronger tone. This contrast effect seems to be sensory, as indicated by Ward's (1990) finding that the effect is not observed when subjects judge, within the same session, the loudness of tones of two different frequencies, unless the frequencies fall within the same critical band. The hypothesis that context affects loudness is also supported by the work of Schneider and Parker (1990), whose procedures did not require subjects to make numerical judgments.

If perceived loudness of a stimulus is affected by the position of the stimulus range, then context effects should be fairly consistent across individual subjects.

Individual subject data. AME functions for individual subjects are plotted in Figure 4. It is evident that the responses of most of the subjects were not affected by stimulus context. In the cases of 10 subjects (Subjects 1-5 and Subjects 9-13), there is very little tendency for AME values for the stimuli at 40,50 , and $60 \mathrm{dBSL}$ to be systematically influenced by the location of the stimulus range. In the case of the other 6 subjects (Subjects 6-8 and Subjects 14-16), AME values tend to be higher when judgments of the stimuli at 40,50 , and $60 \mathrm{dBSL}$ were made in the context of the low range than when they were made in the context of the high range. In no case are the effects of stimulus context so large as to obscure the general form of the individual loudness function. Of the 6 subjects whose judgments were clearly affected by stimulus context, the loudness functions for the low and high ranges were separated on the intensity axis by no more than 5-10 dB.

Thus, the judgments of these subjects are influenced by context, as manifested in a contrast effect in which lower numbers are assigned to a stimulus when it is presented in the context of high-intensity stimuli than when the same stimulus is presented in the context of lowintensity stimuli. The resulting 5-10-dB horizontal shift in the loudness functions of the low and high stimulus ranges corresponds to $1 / 3$ or less of the $30-\mathrm{dB}$ shift predicted from the extreme form of the relative-judgment hypothesis. In stimulus-energy terms, these shifts in the function correspond to $1 / 100$ or less of the total shift predicted from the relative-judgment hypothesis (a 10- $\mathrm{dB}$ shift in intensity is $1 / 100$ as great as a 30 -dB shift in intensity). Thus, it is our conclusion that the results of the 16 subjects presented in Figure 4 were predominantly determined by a tendency of the subjects to match impressions of number size to the subjective magnitudes of the stimu- 


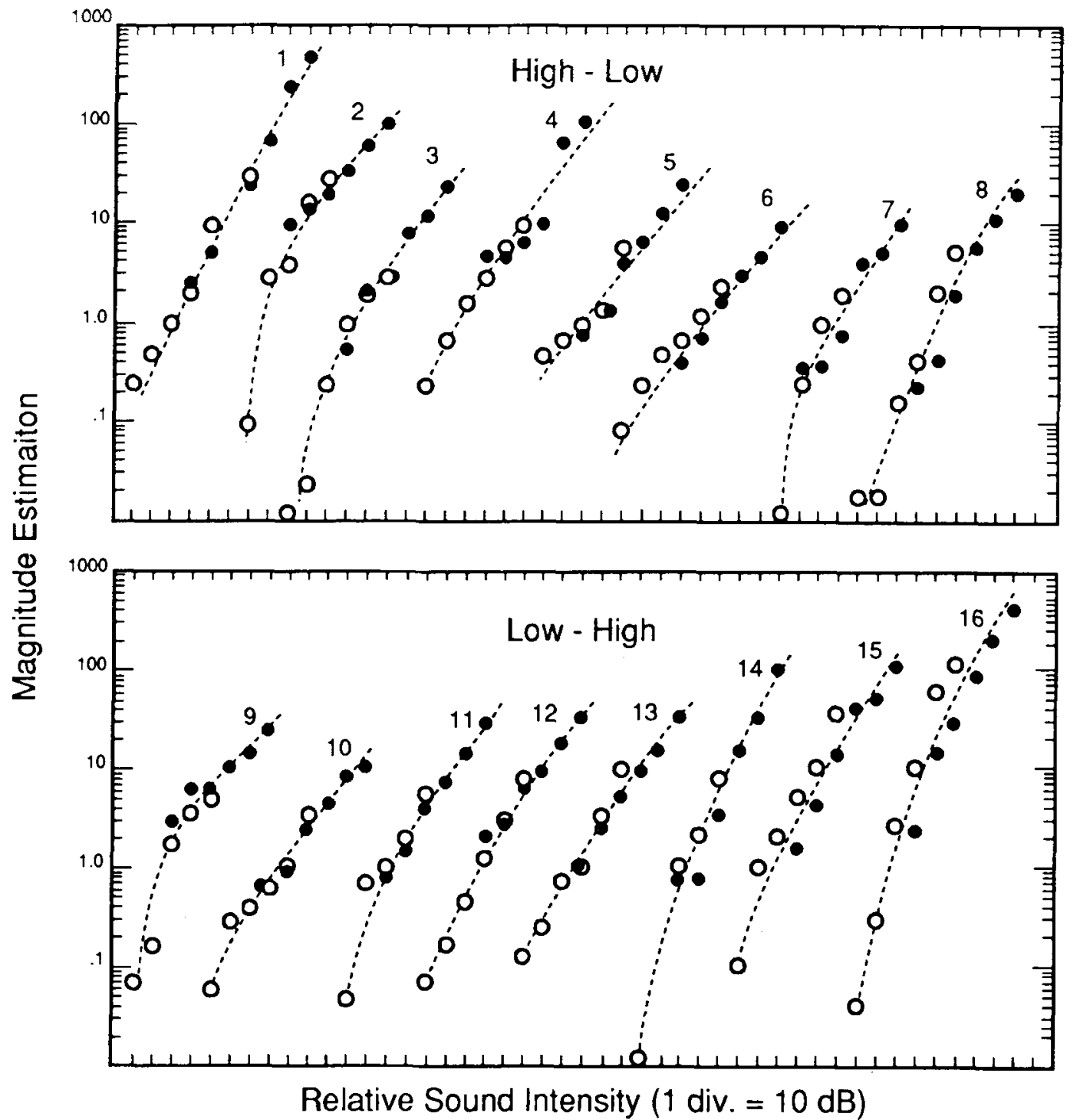

Figure 4. AME judgments of individual subjects as a function of relative sound intensity in decibels. Subjects 1-8 received the high range first, followed by the low range. Subjects 9-16 received the low range first, followed by the high range. For each subject, the highest intensity was $80 \mathrm{dBSL}$. Because of their extremely low values, a few of the data points at the lowest sensation levels are not included in the figure, although they were included in the analysis of group data.

lus, independent of the subjective magnitudes of other stimuli presented in the same session. In most subjects, this tendency is so strong that it overrides any other tendencies that might exist to judge stimuli on a relative basis, in which the same number scale is applied proportionally to both stimulus ranges. About one third of our subjects did, however, show some tendency to be influenced by context, but even in these cases, this tendency does not dominate the subjects' judgments, which are substantially more affected by changes in the intensity of the stimulus. Furthermore, it is possible that these observed context effects were not due to relative judgments at all but were instead the result of sensory contrast.
To ascertain whether or not they had followed the AME instructions, the subjects were asked at the end of the second experimental session to write a brief description of how they performed the task. Most subjects reported that, as instructed, they tried to match their impression of number size to the loudness of the tone. A few reported assigning numbers proportionally so that small numbers went with weak sounds and large numbers went with strong sounds. The 2 subjects for whom data are presented in Figure 5, however, reported judging loudness in terms of categories. Subject 17 reported limiting the range of numbers to 1-30, with the exception that very weak sounds were given numbers less than 1.0. Subject 18 


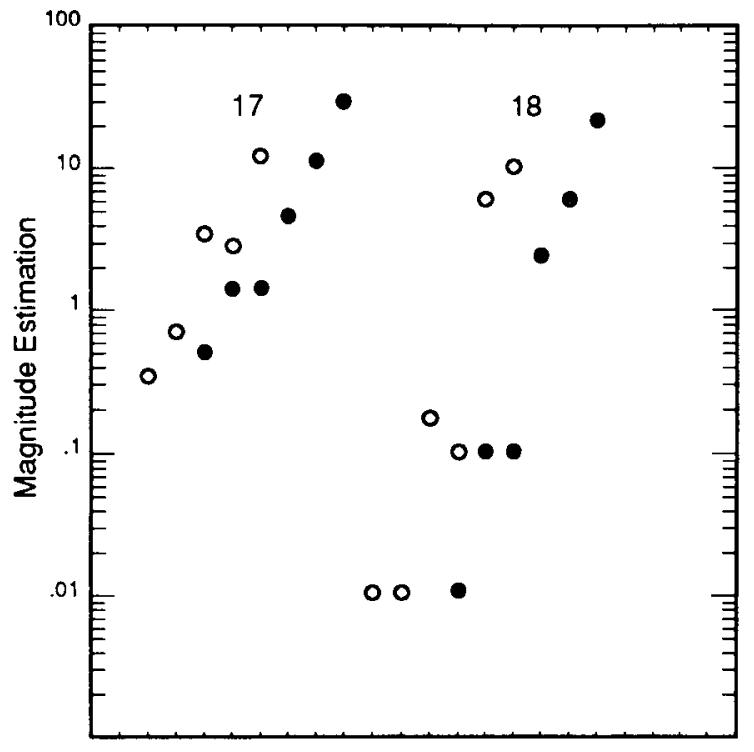

Relative Sound Intensity ( $1 \mathrm{div}=10 \mathrm{~dB}$ )

Figure 5. AME judgments as a function of relative sound intensity for 2 subjects who admitted using category scales in their judgments.

reported using a $0-10$ scale, with the exception that the loudest sound was given a value of 20 . It is interesting that in these two cases in which the subject clearly failed to follow the AME instructions, large amounts of bias occurred. The loudness functions obtained for the low and high ranges are separated by nearly $30 \mathrm{~dB}$, indicating that judgments were almost entirely relative. Thus, these two subjects tended to use the same number range for both the low and high stimulus ranges. This observation clearly indicates that it is essential that subjects carefully follow instructions in AME experiments. We highly recommend that the experimenter confirm, through means independent of examination of the scaling results, that subjects have complied with the instructions.

Marks, Szczesiul, \& Ohlott (1986), using instructions that were essentially the same as those used in AME, also found large individual differences in the degree to which context affected judgments. As in our study, some subjects were virtually unaffected by context, but others were substantially affected.

The AME instructions, in telling the subject to match impressions of number size to impressions of sensation magnitude independently for each stimulus, essentially tell the subject to produce an absolute scale (see Zwislocki, 1991). Thus, the question is whether or not subjects can follow the instructions. Only one number has exactly the same subjactive magnitude as that of the stimulus. There should be nothing arbitrary about the subject's choice of the number. Compliance with instructions should produce judgments that form the basis of an absolute scale with its fixed unit.

\section{EXPERIMENT 2}

The purpose of this experiment was to examine the effects of varying the width of the stimulus range on AME judgments of loudness.

\begin{abstract}
Method
Twenty-two subjects participated in the experiment, and, of these, 2 had participated in Experiment 1. Eleven subjects were first presented with stimuli from a $60-\mathrm{dB}$ range of stimuli $(20,30,40$, $50,60,70$, and $80 \mathrm{dBSL}$ ) followed by a second testing session in which stimuli from a $30-\mathrm{dB}$ stimulus range $(35,40,45,50,55$, 60 , and $65 \mathrm{dBSL}$ ) were presented. The other 11 subjects were first presented with stimuli from the $30-\mathrm{dB}$ range followed by a session in which stimuli from the $60-\mathrm{dB}$ range were presented. The center of both ranges, when expressed in $\mathrm{dBSL}$, was the same- $50 \mathrm{dBSL}$. As in Experiment 1, the important questions are whether or not AME judgments of the stimuli common to both the narrow and wide ranges $(40,50$, and $60 \mathrm{dBSL})$ are significantly different and whether prior experience with one range influences judgments of stimuli in the other. The apparatus was the same as that used in Experiment 1; the procedure was also the same, except that both testing sessions occurred within the same day and, to reduce the total testing time, only two trials were given at each sensation level. The time between sessions was determined by practical considerations and varied between 10 and $60 \mathrm{~min}$.
\end{abstract}

\section{Results and Discussion}

Group data. In Figure 6, the geometric means of AME judgments are plotted as a function of the sensation level of the tone. It is clear that the results of the two groups during both the first session [main effect of range width was $F(1,20)=.908, p>.05$; interaction of range width with sensation level was $F(2,40)=.317, p>.05]$ and the second session [main effect of range width was $F(1,20)=2.19, p>.05$; interaction of range width with sensation level was $F(2,40)=.088, p>.05$ ] were essentially the same for the overlapping segments of the narrow and wide stimulus ranges. Thus, there is no indication that either the position or slope of a sensation-magnitude function obtained by AME is influenced by the context of the width of the intensity range within which stimuli are presented. Comparison of the results of the two groups also showed that they did not differ significantly on judgments of stimuli within either the narrow range [main effect of groups was $F(1,20)=.385, p>.05$; interaction of group with sensation level was $F(6,120)=.55, p>$ .05 ] or the wide range [main effect of groups was $F(1,20)=2.76, p>.05$; interaction of groups with sensation level was $F(6,120)=1.29, p>.05]$. Thus, previous experience with one range did not influence judgments of stimuli in another range.

Furthermore, as seen more clearly in Figure 7, judgments of stimuli common to both ranges were unaffected by changing the width of the range. This conclusion was supported by the lack of significance of either a withinsubject-range main effect $[F(1,20)=2.25, p>.05]$ or an interaction of range with sensation level $[F(2,40)=$ $.169, p>.05]$. The dashed lines in Figure 7 represent predictions from the extreme version of the relative- 


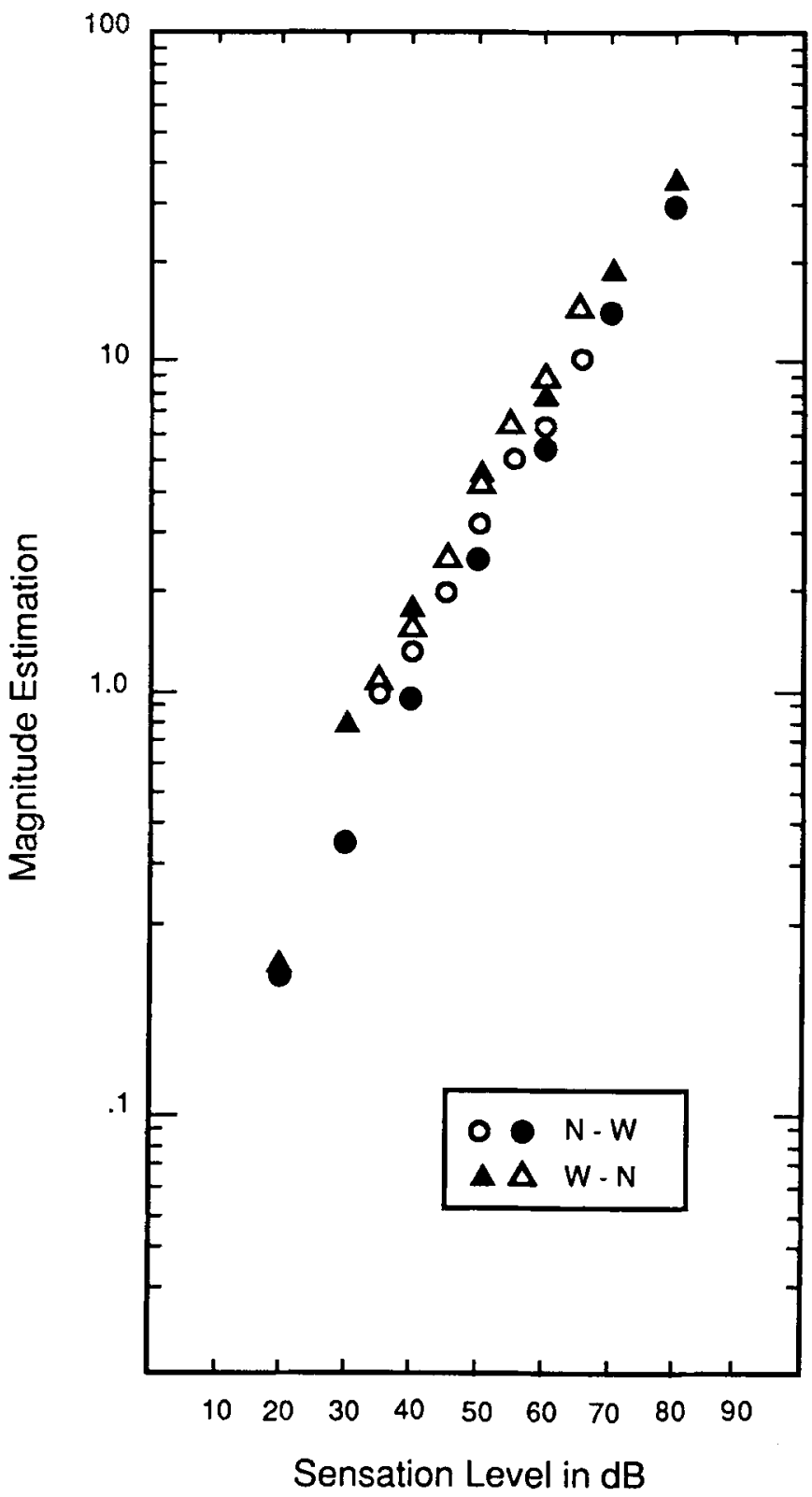

Figure 6. Geometric means of AME judgments as a function of the sensation level of the tone in decibels.

judgment hypothesis, in which subjects continue to use the same number range when the width of the stimulus range is changed. Clearly, this hypothesis is not supported by the results of our experiment. Instead, the subjects' AME responses remain stable for stimuli common to the two ranges when range width is changed. The combined data of the two groups are seen in Figure 8 along with those of 16 of the 22 subjects who were willing to return to the laboratory 4 or 5 weeks later for a final testing session. In this session, the range of sensation levels was $80 \mathrm{~dB}$ (10-90 dBSL). Again, it is clear that AME judgments were little affected by the width of the stimulus range.
Finally, in Figure 9, the average results obtained for the 30 - and $60-\mathrm{dB}$ ranges from the 22 subjects of Experiment 2 are plotted for comparison with the average results of the 16 subjects of Experiment 1. A notable consistency across experiments of the absolute values of AME judgments is seen in this figure. In addition, the responses obtained in the final phase of Experiment 2 with the 80-dB range (not shown in Figure 9, but seen in Figure 8) and the responses of Experiment 1 were significantly different for only the $20-\mathrm{dB}$ sensation level $[F(1,90)=6.83$, $p<.05]$. This loudness function is in substantial agreement with the absolute values of the AME judgments of loudness of a $1000-\mathrm{Hz}$ tone made by the subjects tested 


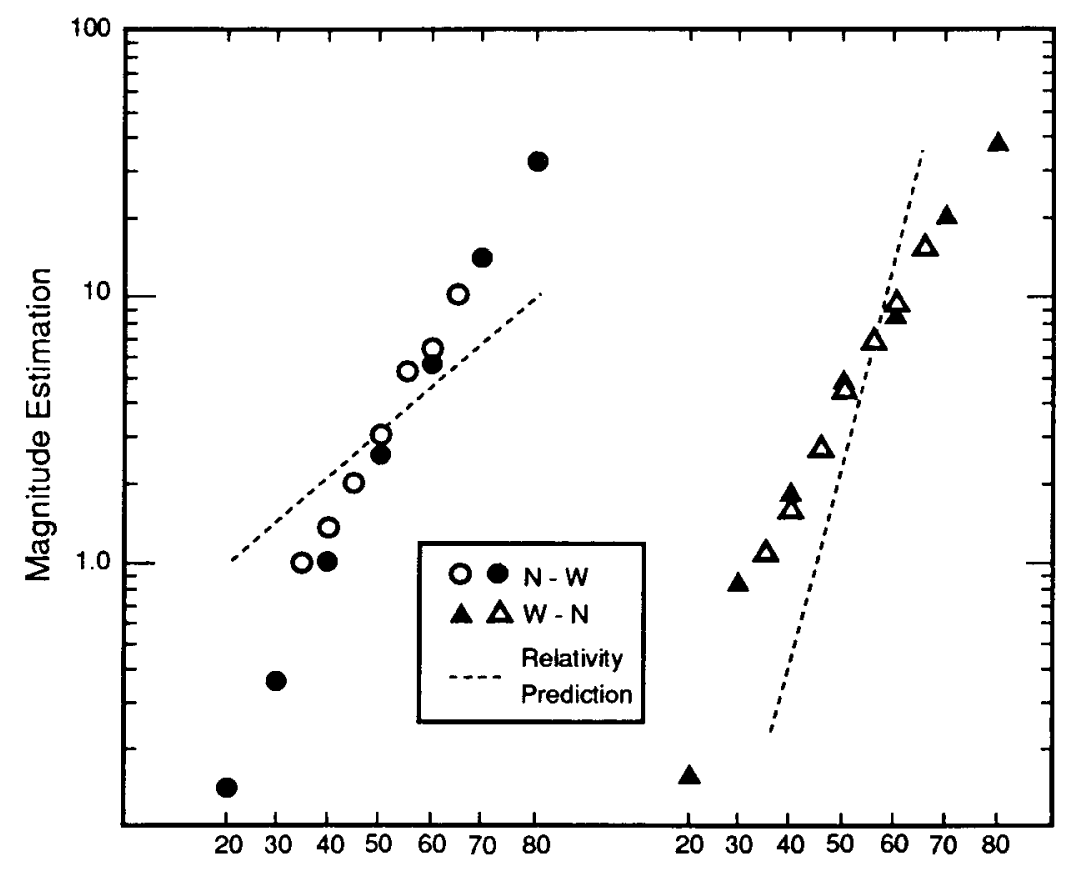

Sensation Level in $\mathrm{dB}$

Figure 7. Geometric means of AME judgments as a function of sensation level for subjects shifted from narrow to wide range $(O)$ and subjects shifted from wide to narrow range $(\Delta \Delta)$.

by Zwislocki and Goodman (1980). In general, it can be said that the shape and the absolute position of the loudness function is affected very little by stimulus-range conditions. These results are in sharp contrast to the numerous demonstrations that variation of stimulus range has a substantial effect on magnitude-estimation data obtained both with instructions other than those used in AME (e.g., Foley, Cross, Foley, \& Reeder, 1983; Frederiksen, 1975; Montgomery, 1975) and with a standard stimulus with modulus (Ahlström \& Baird, 1989). In particular, there is no evidence that subjects, in performing AME, commit what Poulton (1979) has identified in magnitude estimation as the stimulus-range equalizing bias, in which the subjects use much the same geometric range of numbers, whatever the size of the geometric stimulus range. The results of Teghtsoonian (1973) and Teghtsoonian and Teghtsoonian (1978) are in closer agreement with ours than are those of the other studies mentioned above. Although the Teghtsoonian studies demonstrated range effects, they were substantial only when ranges were smaller than those used in our study.

Individual subject data. AME functions for individual subjects are plotted in Figure 10. It is evident that the width of the stimulus range had little, if any, effect on the judgments of most subjects. Specifically, in AME there is no tendency for the slopes of the sensation-magnitude functions to be higher for narrow than for wide stimulus ranges, as has been demonstrated to be the case in magnitude estimation (e.g., Foley, et al., 1983; Frederiksen, 1975; Montgomery, 1975; Teghtsoonian, 1973; Teghtsoonian \& Teghtsoonian, 1978). A power function was fitted to each subject's data over the range of $30-80 \mathrm{dBSL}$, within which a single exponent describes the function. The results showed that the mean exponent was essentially identical for the narrow (mean exponent, .359) and the wide (mean exponent, .357) ranges. The correlation between exponents in the two ranges was significant $(r=.58, p<$ .01 ), indicating stability of judgments over sessions (also see Collins \& Gescheider, 1989). Also, with the exception of Subject 22, no substantial differences in intercepts for the narrow- and wide-range functions are seen. The averages of the antilogs of the intercepts of the best-fitting $\log$ - $\log$ functions were .095 and .108 for the narrow and wide ranges, respectively. The intercept values of individual subjects that were obtained for the two ranges were significantly correlated $(r=.67, p<.01)$, indicating that the absolute position, as well as the slope of the loudness functions, tended to be reliable over sessions and different range widths.

Why were the AME judgments of several of the subjects of Experiment 1 affected by changes in the position of the stimulus range, whereas the judgments of only 1 subject in Experiment 2 were affected by changes in its width? For some subjects, according to a sensory con- 


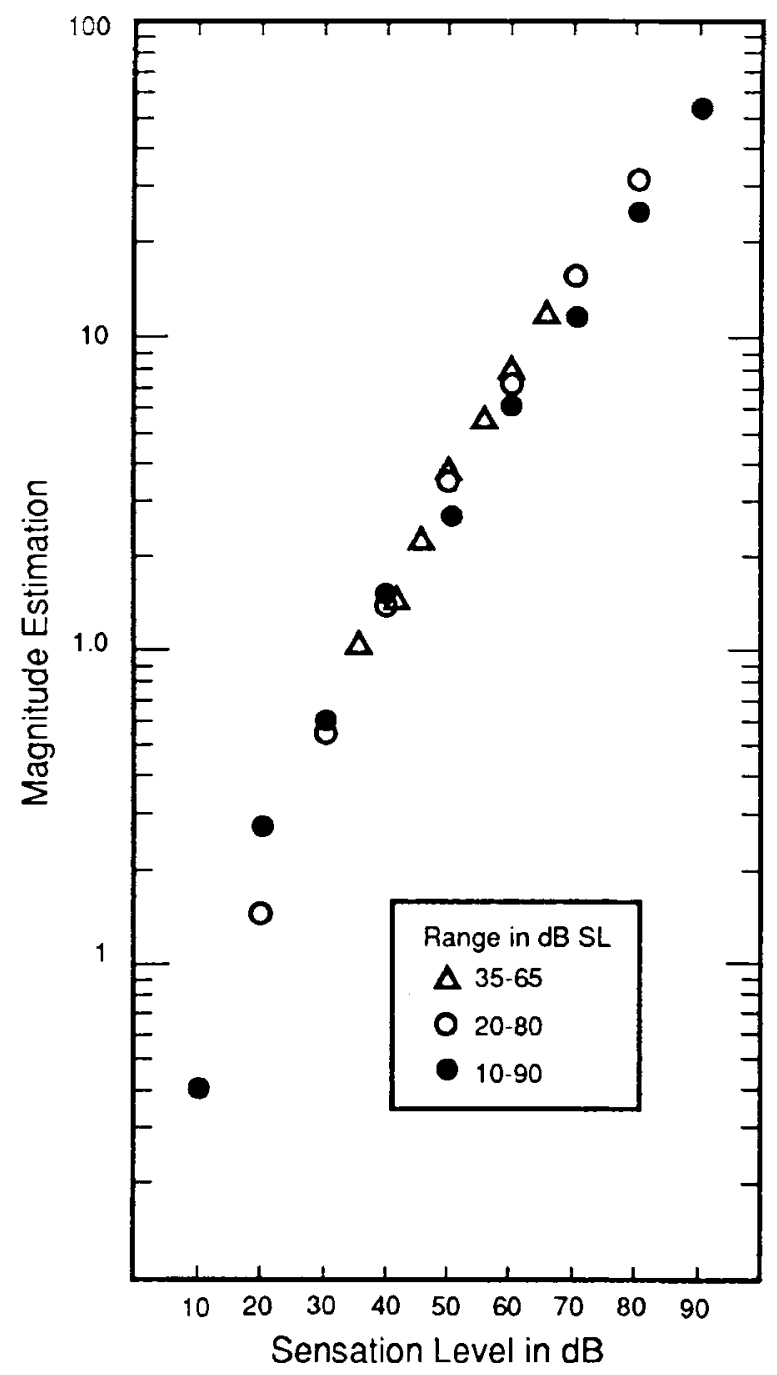

Figure 8. Geometric means of AME judgments as a function of sensation level for subjects tested with stimulus ranges of 30,60 , and $80 \mathrm{~dB}$.

trast hypothesis, hearing intense tones within a session may have reduced the loudness of moderately intense tones, whereas hearing weak tones within a different session may have increased the loudness of these same tones. On the other hand, in Experiment 2, the moderately intense tones presented within the wide range were heard in the context of both weaker and stronger ones presented within the same session. Consequently, under these conditions, the tendency for more intense tones to reduce the loudness of moderately intense tones may have been canceled by the opposing tendency of weak tones to enhance the loudness of these tones. The result would be that the loudnesses of the moderately intense stimuli within the narrow 35-65-dB range would not be affected by extending the range to $20-80 \mathrm{~dB}$. The remaining problem is to explain why the judgments of some subjects in Experiment 1 were affected by stimulus context, whereas those of others were not.

\section{CONCLUSION}

The procedure of AME is based on the observation that subjects, by matching their impression of number size to their impression of the subjective magnitude of a stimulus, produce natural psychophysical scales (see Zwislocki, 1991) that, for each individual subject, has a fixed unit. When this behavior is thwarted by using a standard stimulus with a modulus that does not correspond to a subject's natural scale, bias occurs. Furthermore, when subjects are encouraged to judge sensations relatively, as they may be when given other magnitude-estimation instructions or category-scaling instructions, strong stimulus-context bias may occur. AME is a technique that appears to minimize certain biases by providing the subjects with a task that is consistent with their natural tendency to match subjective magnitudes. It should be pointed out, however, that

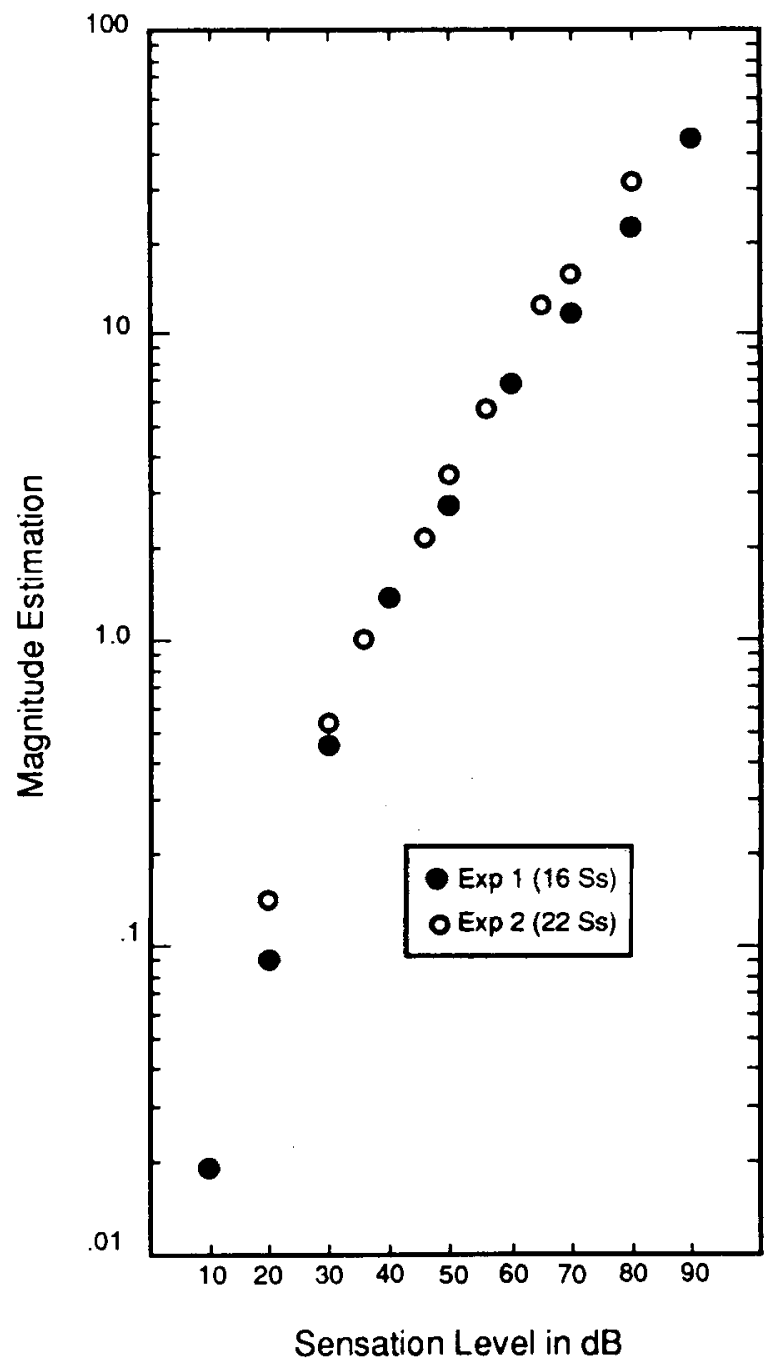

Figure 9. Geometric means of AME judgments as a function of the sensation level of the tone in decibels for 16 subjects of Experiment 1 and 22 subjects of Experiment 2. 

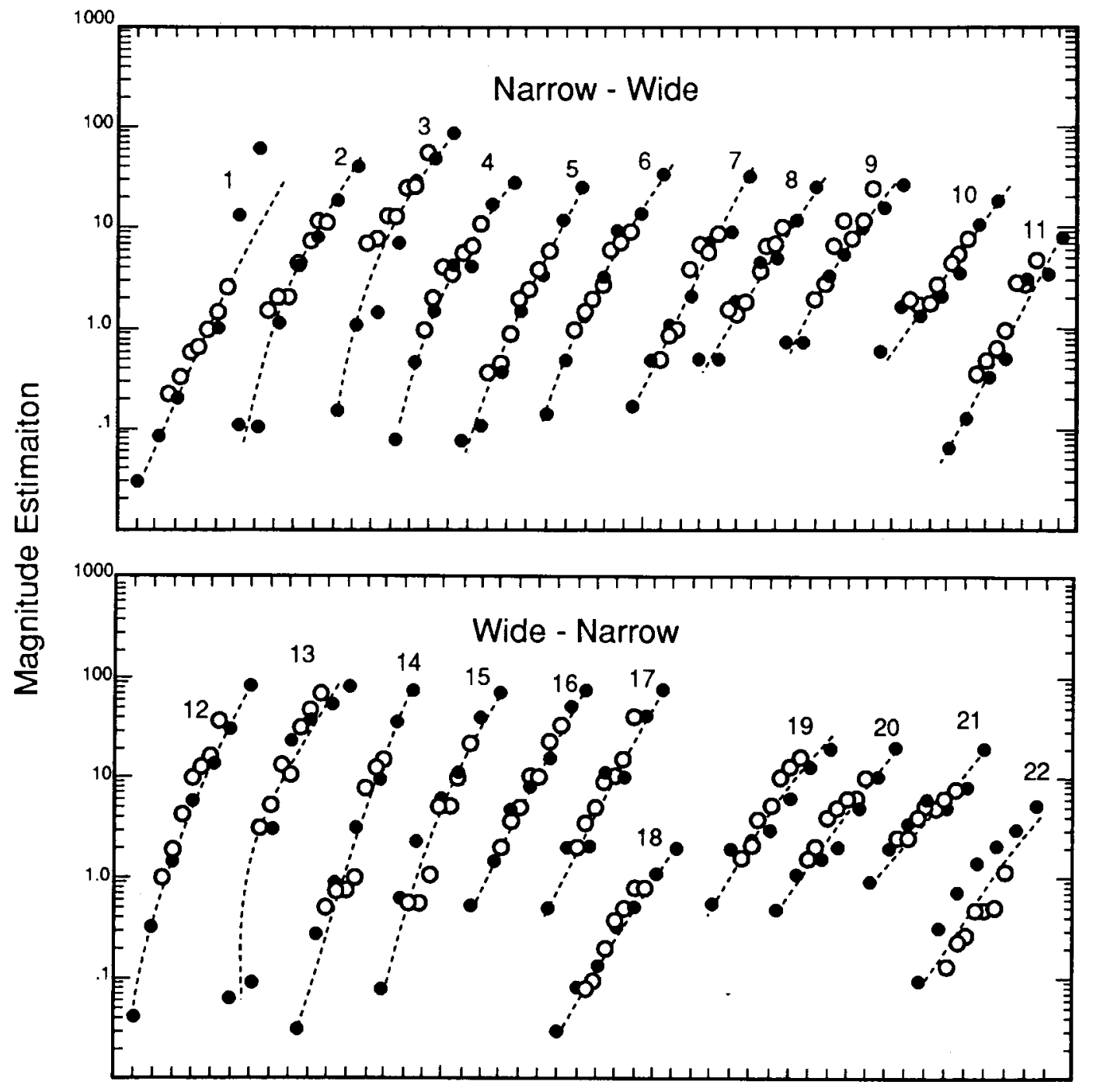

Relative Sound Intensity ( 1 div. $=10 \mathrm{~dB})$

Figure 10. AME judgments of individual subjects as a function of relative sound intensity. The highest intensity was 80 dBSL.

bias associated with the nonlinear use of numbers is not eliminated through the use of AME unless certain additional procedures are employed to correct for such nonlinearities (see Collins \& Gescheider, 1989; Zwislocki, 1983a). The use of these procedures results in estimations, for individual subjects, of the function describing the relationship between assigned numbers and sensation magnitudes that is used to correct the individual's psychophysical scale.

\section{REFERENCES}

AHLström, R., \& Baird, J. C. (1989). Shift in stimulus range and the exponent of the power function for loudness. Perception \& Psychophysics, 46, 603-607.

BolanowsKI, S. J., JR. (1987). Contourless stimuli produce binocular brightness summation. Vision Research, 27, 1943-1951.
BolanowsKI, S. J., JR., ZWISLOCKI, J. J., \& Gescheider, G. A. (1991). Intersensory generality and psychological units. In S. J. Bolanowski, Jr., \& G. A. Gescheider (Eds.), Ratio scaling of psychological magnitude: A tribute to the memory of S. S. Stevens. Hillsdale, NJ: Erlbaum.

Collins, A. A., Gescheider, G. A. (1989). The measurement of loudness in children and adults by absolute magnitude estimation and cross-modality matching. Journal of the Acoustical Society of America, 85, 2012-2021.

Foley, H. J., Cross, D. V., Foley, M. A., Reeder, R. (1983). Stimulus range, number of categories and the "virtual" exponent. Perception \& Psychophysics, 34, 505-512.

Foley, H. J., Cross, D. V., \& O'Reilly, J. A. (1990). Pervasiveness and magnitude of context effects: Evidence for the relativity of absolute magnitude estimation. Perception \& Psychophysics, 48, 551-558. FrederiksEN, J. R. (1975). Two models for psychophysical judgment: Scale invariance with changes in stimulus range. Perception \& Psychophysics, 17, 147-157.

Gescheider, G. A. (1988). Psychophysical scaling. Annual Review of Psychology, 39, 169-200. 
Gescheider, G. A., \& Bolanowski, S. J., JR. (1991). Final comments on ratio scaling of psychological magnitude. In S. J. Bolanowski, Jr., \& G. A. Gescheider (Eds.), Ratio scaling of psychological magnitude: $A$ tribute to the memory of $S$. S. Stevens. Hillsdale, NJ: Erlbaum.

Hellman, R. P. (1976). Growth of loudness at 1000 and $3000 \mathrm{~Hz}$. Journal of the Acoustical Society of America, 60, 672-679.

Hellman, R. P., Zwislocki, J. J. (1961). Some factors affecting the estimation of loudness. Journal of the Acoustical Society of America, 33, 687-694.

Hellman, R. P., \& Zwislock1, J. J. (1963). Monaural loudness function at $1000 \mathrm{cps}$ and interaural summation. Journal of the Acoustical Society of America, 35, 856-865.

Hellman, R. P., Zwislocki, J. J. (1964). Loudness function of a $1000 \mathrm{cps}$ tone in the presence of a masking noise. Journal of the Acoustical Society of America, 36, 1618-1627.

Hellman, R. P., \& ZWISLOCKI, J. J. (1968). Loudness determination at low sound frequencies. Joumal of the Acoustical Society of America, 43, 60-64.

LUCE, R. D., \& TUKEY, J. (1964). Simultaneous conjoint measurement: A new type of fundamental measurement. Journal of Mathematical Psychology, 1, 1-27.

Marks, L. E., Szczesiul, R., \& OHlott, P. (1986). On the crossmodality perception of intensity. Journal of Experimental Psychology: Human Perception \& Performance, 12, 517-534.

Mellers, B. A. (1983). Evidence against "absolute" scaling. Perception \& Psychophysics, 33, 523-526.

Montgomery, H. (1975). Direct estimation: Effect of methodological factors on scale type. Scandinavian Joumal of Psychology, 16, 19-29.

Poulton, E. C. (1979). Models for biases in judging sensory magnitude. Psychological Bulletin, 86, 777-803.

Rowley, R. R., \& STUdebaker, G. A. (1969). Monaural loudnessintensity relationships for a $1000 \mathrm{~Hz}$ tone. Journal of the Acoustical Society of America, 45, 1193-1205.

SChneider, B., \& Parker, S. (1990). Does stimulus context affect loudness or only loudness judgments? Perception \& Psychophysics, 48, 409-418.

SteVens, S. S. (1951). Mathematics, measurement and psychophysics. In S. S. Stevens (Ed.), Handbook of experimental psychology (pp. 149). New York: Wiley.

STEVENS, S. S. (1956). The direct estimation of sensory magnitude: Loudness. American Journal of Psychology, 69, 1-25.

STEVens, S. S. (1975). Psychophysics: Introduction to its perceptual, neural, and social prospects. New York: Wiley.

TEGHTSOONIAN, R. (1973). Range effects in psychophysical scaling and a revision of Stevens' Law. American Joumal of Psychology, 86, 3-27.
Teghtsoonian, R., \& Teghtsoonian, M. (1978). Range and regression effects in magnitude scaling. Perception \& Psychophysics, 24, 305-314.

Verrillo, R. T., Fraioli, A. J., \& Smith, R. L. (1969). Sensation magnitude of vibrotactile stimuli. Perception \& Psychophysics, 6, 366-372

WARD, L. M. (1982). Mixed-modality psychophysical scaling: Sequential dependencies and other properties. Perception \& Psychophysics, 31, 53-62.

WARD, L. M. (1985). Mixed-modality psychophysical scaling: Interand intramodality sequential dependencies as a function of lag. Perception \& Psychophysics, 38, 512-522.

WARD, L. M. (1986). Mixed-modality psychophysical scaling: Double cross-modality matching for "difficult" continua. Perception \& Psychophysics, 39, 407-417.

WARD, L. M. (1987). Remembrance of sounds past: Memory and psychophysical scaling. Joumal of Experimental Psychology: Human Perception \& Performance, 13, 216-227.

WARD, L. M. (1990). Critical bands and mixed-frequency scaling: Sequential dependencies, equal-loudness contours, and power function exponents. Perception \& Psychophysics, 47, 551-562.

ZwISLOCKı, J. J. (1978). Absolute scaling. Journal of the Acoustical Society of America, 63, S16. (Abstract).

ZwISLOCKI, J. J. (1983a). Absolute and other scales: Question of validity. Perception \& Psychophysics, 33, 593-594.

ZwISLOCKI, J. J. (1983b). Group and individual relations between sensation magnitudes and their numerical estimates. Perception \& Psychophysics, 33, 460-468.

ZwISLOCKI, J. J. (1991). Natural measurement. In S. J. Bolanowski, Jr., \& G. A. Gescheider (Eds.), Ratio scaling of psychological magnitude: A tribute to the memory of $S$. $S$. Stevens. Hillsdale, NJ: Erlbaum.

ZwISLOCKI, J. J., \& Goodman, D. A. (1980). Absolute scaling of sensory magnitudes: A validation. Perception \& Psychophysics, 28, 28-38.

\section{NOTE}

1. Twenty-one subjects were tested, but the data of 3 subjects were not used in the analysis because of evidence that they were judging the aversiveness, rather than the loudness, of the intense tones.

(Manuscript received June 27, 1990; revision accepted for publication March 1, 1991.) 